\title{
D! ỨNG THUỐC ĐộNG KINH CARBAMAZEPINE: TRƯỜNG HợP STEVENS-JOHNSON
}

\author{
Nguyễn Văn Khiêm, Thục Thanh Huyền, Nguyễn Thị Vân Anh, \\ Lê Quỳnh Chi, Lê Thị Minh Hương \\ Bệnh viện Nhi Trung ương
}

\section{TÓM TẮT}

Hội chứng Steven - Johnson (SJS) là một phản ứng nặng ở da do nhiều nguyên nhân, có thể gây nguy hiểm đến tính mạng hoặc để lại nhiêu di chứng nặng nề đặc biệt ở trẻ em. Carbamazepine là một trong những nguyên nhân thường gặp. Có mối quan hệ giữa SJS, carbamazepine và $H L A-B^{*} 1502$ trên người châu Á đã được nhiều nghiên cứu chỉ ra. Báo cáo về ca lâm sàng điển hình tại khoa Miễn dịch dị ứng - Bệnh viện Nhi Trung ương về trường hợp trẻ mắc SJS sau khi sử dụng carbamazepine, nhóm nghiên cứu muốn góp thêm một bằng chứng về mối quan hệ giữa ba yếu tố kể trên đối với người Việt Nam.

Từ khoá: Stevens - Johnson, carbamazepine, HLA-B*1502

\section{ABSTRACT \\ ALLERGY OF CARBAMAZEPINE A CASE OF STEVENS-JOHNSON}

Stevens-Johnson syndrome (SJS) is a rare but life-threatening skin reaction disease caused by multiple causes, especially in children. Carbamazepine is one of the most common seen causes. The correlation among SJS, Carbamazepine and HLA-B*1502 in Asian community has been reported. This specific case report about Carbamazepine-induced SJS in The department of Allergy - Immunology - Rheumatology, Vietnam National Children's Hospital, we would like to contribute evidence about correlation of the above - mentioned factors in Vietnamese patients.

Key words: Stevens Johnson, carbamazepine, HLA-B*1502. 


\section{1. ĐẠTT VẤN ĐỀ}

Hội chứng Stevens-Johnson (SJS) là phản ứng ở da hiếm gặp nhưng nguy cơ tử vong và để lại di chứng cao. Các triệu chứng điển hình của SJS là biểu hiện hồng ban đa dạng, đau rát, phỏng rộp và viêm loét niêm mạc từ 2 hốc tự nhiên trở lên, dấu hiệu Nikosky âm tính, có hoặc không có tổn thương nội tạng, tổng diện tích tổn thương bọng nước dưới $10 \%$ diện tích cơ thể. Nghiên cứu gần đây đã chỉ ra tỷ lệ mắc SJS/ TEN ở trẻ em cao hơn so với người trưởng thành, với tỷ lệ là 7.5/100000, trong đó trẻ từ 11-15 tuổi có tỷ lệ mắc cao nhất là 38.4/100000. Mặc dù tỷ lệ thương tật do SJS/TEN ở trẻ nhỏ tương đối thấp, chỉ từ 0.4-5.3 trên một triệu bệnh nhi, nhưng tỷ lệ tử vong lại rất cao, $16.7 \%-44 \%$. Do đó, việc kiểm soát nguyên nhân cũng như điều trị SJS/TEN là một yêu cầu cấp thiết cho các nhà khoa học [1].

Có tới $80 \%$ nguyên nhân gây ra SJS/TEN là do thuốc như kháng sinh, thuốc điều trị động kinh và một số thuốc chống viêm nonsteroid với cơ chế bệnh sinh vẫn chưa hoàn toàn sáng tỏ. Nhiều giả thuyết cho rằng sự quá mẫn của hệ thống miễn dịch cũng như sự hủy hoại keratin do chết tế bào là những nguyên nhân chính gây ra bệnh lý này [1], [2].

Carbamazepine (Tegretol) là thuốc chống co giật được sử dụng khá rộng rãi và hiệu quả trong điều trị động kinh, đau dây thần kinh sinh ba, rối loạn giấc ngủ, rối loạn thần kinh khác (nhức đầu và tic cơ bắp). Tuy nhiên tegretol cũng chính là nguyên nhân hàng đầu gây dị ứng thuốc nặng với biểu hiện lâm sàng là Hội chứng
Stevens - Johnson (SJS). Theo khảo sát gần đây, carbamazepine gây ra khoảng từ 1/1000 đến $1 / 10000$ ca trên lâm sàng. Nghiên cứu của Nguyễn Khắc Dũng tại Việt Nam cho kết quả carpamazepine là nguyên nhân hàng đầu gây SJS/TEN với tỷ lệ 18.38\% [2].

Yếu tố di truyền đóng vai trò khá quan trọng liên qua đến dị ứng tegretol, đặc biệt ở người châu Á. Một số nghiên cứu nhận thấy ở chủng tộc người châu Á các cá thể mang alen HLA-B*1502 dị ứng thuốc chống động kinh carbamazepine có nguy cơ biểu hiện SJS/TEN. Hậu quả nặng nề của SJS/TEN còn khá cao, do đó tại các nước phát triển, khi bệnh nhân có chỉ định điều trị carbamazepine thường được xét nghiệm HLA$B^{*} 1502$ trước khi dùng [3], [4], [5].

Chính vì vậy, báo cáo ca lâm sàng này sẽ minh chứng cho việc xác định allen HLA-B*1502 cho bệnh nhi có chỉ định dùng carbamazepine là cần thiết.

\section{BÁO CÁO CA LÂM SÀNG}

Thông tin bệnh nhân: Hồ Văn D; sinh ngày 14/10/2004; giới tính: Nam; dân tộc: Kinh; Mã số bệnh án: 190638041; nhập vào khoa Miễn dịchDị ứng-Khớp ngày: 25/05/2020.

Tiền sử: Trẻ được chẩn đoán chậm phát triển trí tuệ từ nhỏ. Cách đây nửa năm, bệnh nhân được chẩn đoán động kinh tại Bệnh viện Nhi Trung ương và được điều trị thuốc chống động kinh keppra như sau: Từ tháng 10/2019 đến $1 / 2020$, vì chưa kiểm soát được triệu chứng động kinh nên keppra được tăng liều từ 1000 lên đến 1500-2000 mg/ngày; sau đó kết hợp 
topamax liều tăng dần từ 50 đến $150 \mathrm{mg} / \mathrm{ngày}$. Với các thuốc điều trị kết hợp trên bệnh nhân hết co giật nhưng còn quay đầu trái. Tháng 5/2020, bệnh nhân xuất hiện cơn co giật cục bộ, đến tái khám tại Bệnh viện Nhi Trung ương và được điều chỉnh phác đồ: Keppra $500 \mathrm{mg} /$ ngày, topamax $200 \mathrm{mg} / \mathrm{ngày}$ và thêm tegretol $1600 \mathrm{mg} / \mathrm{ngày}$. Bệnh nhân đã được dặn dò theo dõi sát các biểu hiện dị ứng và khám lại ngay nếu có dấu hiệu nghi ngờ. Uống tới ngày thứ 12 , bệnh nhân xuất hiện sưng môi, sốt nhẹ, đỏ mắt và nổi hồng ban trên da.

Bệnh nhân vào viện (ngày thứ 13 sau sử dụng carbamazepine) với các triệu chứng: Toàn trạng: trẻ tỉnh táo, hơi mệt, nhiều nốt hồng ban đa hình thái ở mặt và rải rác toàn thân với diện tích tổn thương khoảng 10\% diện tích da cơ thể, kèm theo viêm niêm mạc miệng (sưng rộp môi, loét niêm mạc miệng), viêm kết mạc mắt (mắt nề đỏ, nhiều gỉ mắt, không giảm thị lực), dấu hiệu Nikolsky dương tính.

Chỉ số sinh tồn: Nhiệt độ $36,8^{\circ} \mathrm{C}$; Huyết áp 110/65mmHg, Nhịp tim 75 chu kỳ/phút; Nhịp thở 17 lần/phút; Chiều cao $165 \mathrm{~cm}$; Cân nặng $53 \mathrm{~kg}$.

Các cơ quan khác như tim, phổi, tiêu hóa bình thường, gan, lách, hạch không to.

Cận lâm sàng: CRP 62 mg/dL, WBC: 11,04 T/l, xét nghiệm sinh hóa về chức năng thận, gan và các men gan trong giới hạn bình thường; Xquang ngực không có dấu hiệu bất thường. Xét nghiệm HLA-B*1502 dương tính.

Chẩn đoán xác định: Hội chứng StevenJohnson do thuốc carbamazepine, HLA-B*1502 dương tính/ Động kinh/ chậm phát triển trí tuệ.

Bệnh nhân được hội chẩn với chuyên khoa thần kinh và điều trị phác đồ:

- Các thuốc chống viêm dị ứng:

Methylprednisolon $2 \mathrm{mg} / \mathrm{kg} / \mathrm{ngày}$ tiêm tĩnh mạch chậm chia 2 lần trong vòng 5 ngày, sau chuyển sang uống prednisolon $1 \mathrm{mg} / \mathrm{kg} / \mathrm{ngày,} \mathrm{liều}$ giảm dần trong vòng 5-6 ngày sau đó dừng thuốc.

- Điều trị triệu chứng:

+ Chăm sóc các tổn thương niêm mạc như vệ sinh kỹ các niêm mạc miệng và mắt hàng ngày bằng dung dịch muối sinh lý, nhỏ nước mắt tự nhiên, vitamin $A$ và tobrex.

+ Chăm sóc vùng da tổn thương theo quy trình chăm sóc da.

+ Bù nước điện giải

- Điều trị động kinh: Dò liều tăng dần để đạt liều điều trị và duy trì.

+ Keppra 500mg: từ $3-5$ viên/ngày.

+ Topamax 50mg: từ 4-7 viên/ngày.

+ Từ ngày thứ 8 sau nhập viện thêm depakine $200 \mathrm{mg} 2$ viên/ngày.

Bệnh nhân được theo dõi và điều trị nội trú trong vòng 14 ngày. Tiến triển bệnh tốt dần, bệnh nhân kiểm soát được cơn giật và các tổn thương da, niêm mạc dần hồi phục, không để lại biến chứng.

Bệnh nhân được xuất viện với tình trạng ổn định. Cận lâm sàng: CRP 2,54 mg/dL, WBC: 11,7 T/l. 
TẠP CHÍ NHI KHOA 2020, 13, 5

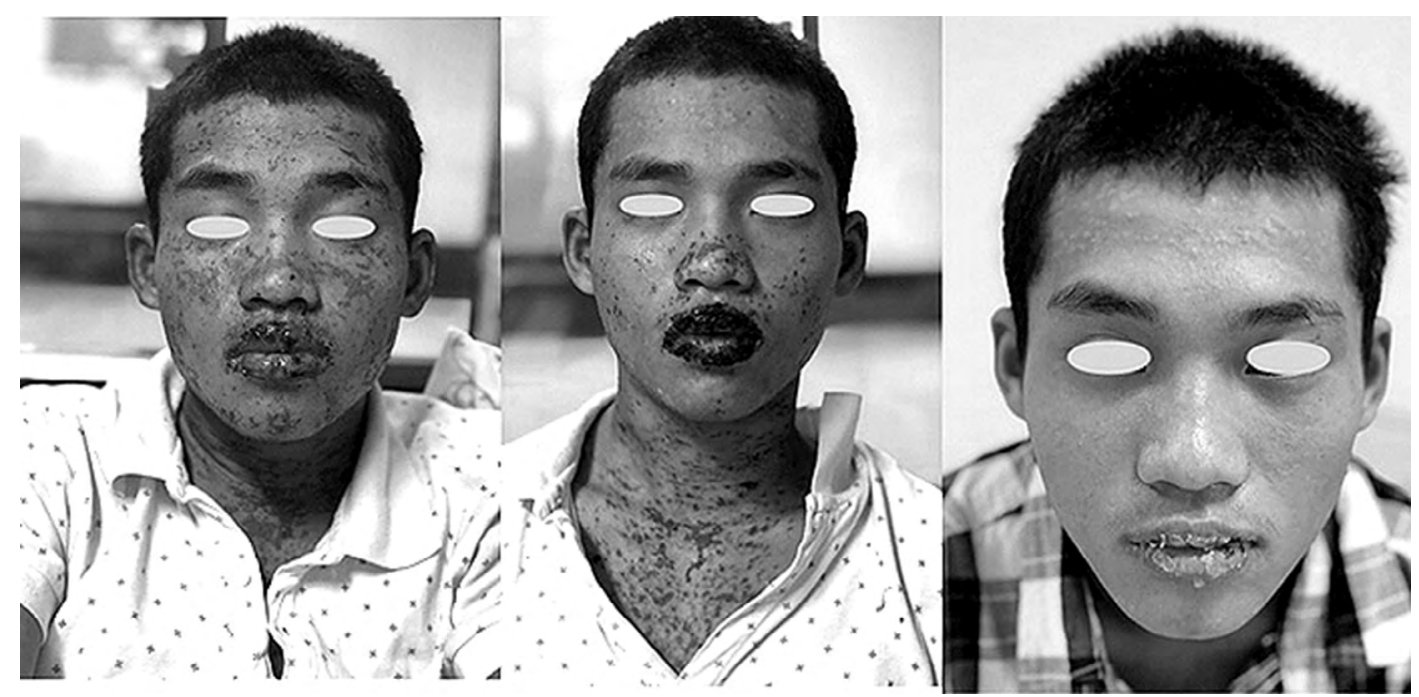

Hình 1. Hình ảnh bệnh nhân trước và sau điều trị lở loét ở miệng, viêm mắt cải thiện rõ rệt
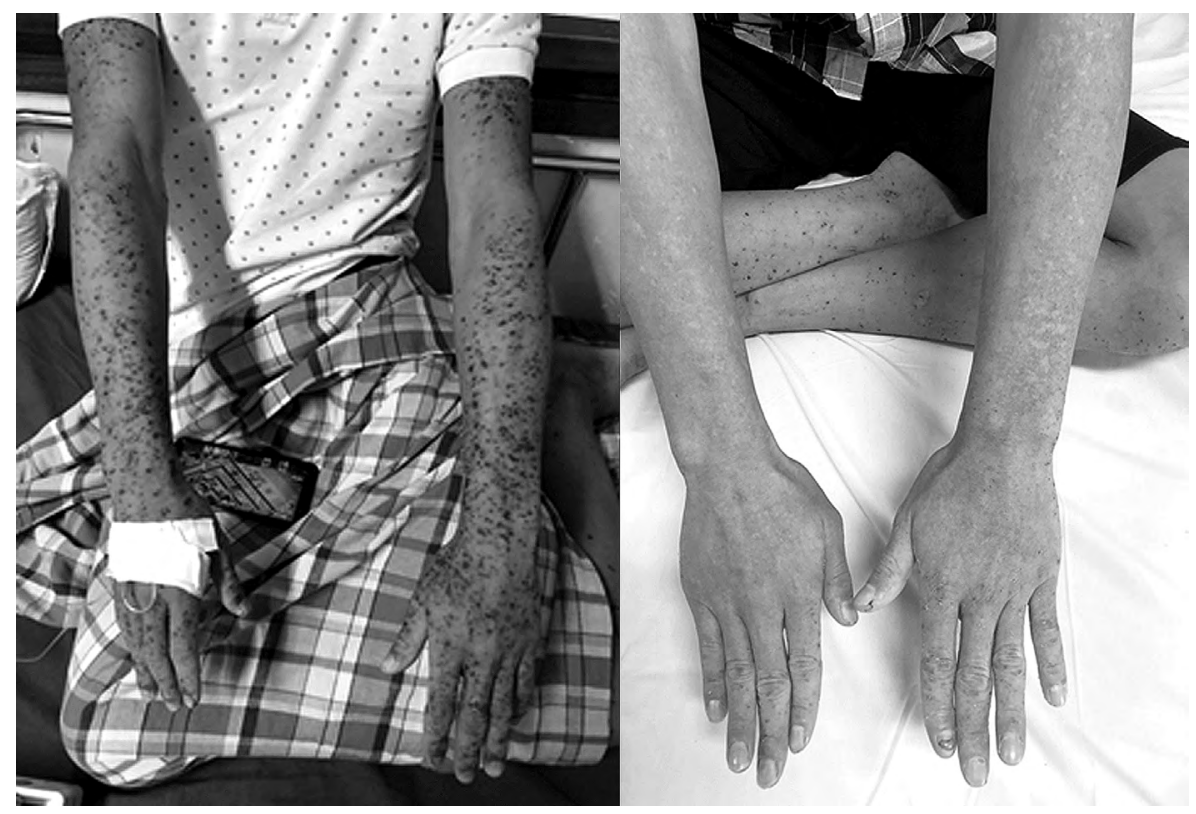

Hình 2. Hình ảnh bệnh nhân trước và sau điều trị

\section{BÀN LUẬN}

Động kinh là một bệnh lý thường gặp trong chuyên khoa thần kinh nhi khoa, với tỷ lệ khoảng 1\%-2\% tổng số trẻ. Carbamazepine là dẫn xuất aminostilen với một nhóm carbamyl ở vị trí số 5 có tác dụng chống động kinh bằng cách tác động trước sinap để chẹn giải phóng chất dẫn truyền thần kinh, làm giảm dẫn truyền qua sinap. Để kiểm soát bệnh lý này nhất là thể động kinh cục bộ, carmapazepine thường được lựa chọn cho các cơn động kinh cục bộ, vắng ý thức, để tăng tác dụng, bệnh nhân này đã được sử dụng carmapazepine kết hợp với levetiracetam [6]. 
Tác dụng phụ đáng sợ nhất của carbamazepine là SJS/TEN, thường sẽ xảy ra trong 2 tháng đầu sử dụng thuốc. Dị ứng carbamazepine là đáp ứng miễn dịch thể quá mẫn muộn. Theo nhiên cứu gần đay tại Bệnh viện Nhi Trung ương cho thấy biểu hiện lâm sàng dị ứng carbamazepine ở trẻ em chủ yếu là hội chứng Stevens - Johnson chiếm $66,7 \%$ [7].

Theo kết quả của bệnh nhân trong báo cáo này cho thấy các dấu hiệu dị ứng xuất hiện sau 12 ngày dùng carbamazepine, đây là khoảng thời gian phù hợp với đặc điểm mẫn cảm chậm, tương tự kết quả của nhiều nghiên cứu đã công bố trước đây. Bệnh nhân này đã được bác sĩ cảnh báo về khả năng dị ứng thuốc nên đã đến khám lại ngay sau khi có biểu hiện dị ứng. Bệnh nhân nhanh chóng được chẩn đoán SJS do thuốc carbamazepine bằng khai thác tiền sử dùng thuốc, các dấu hiệu lâm sàng điển hình ở da là hồng ban đa dạng, phỏng rộp với diện tích tổn thương $10 \%$ và tổn thương niêm mạc 2 hốc tự nhiên (miệng, mắt) [5], [6],[7].

Như chúng ta đã biết, cá thể có alen HLA-B*1502 dương tính thường có nguy cơ tăng nhạy cảm với carbamazepine, dẫn đến các phản ứng dị ứng, đặc biệt phản ứng nặng như SJS. Cơ chế chưa rõ nhiều giả thuyết cho rằng alen $H L A-B^{*} 1502$ có khả năng sản xuất ra các chất ngoại sinh làm hoạt hoá tế bào $T$ gây độc tế bào, qua đó gây huỷ hoại các tế bào thượng bì trên bề mặt da thông qua cơ chế Fas và FasL [2], [3], [4].

Trong điều trị bệnh động kinh, việc sử dụng thuốc chống động kinh kéo dài với các liều khác nhau là một điều bắt buộc. Chính vì vậy, việc xét nghiệm tìm gene HLA-B*1502 để dự phòng SJS/ TEN trước khi dùng carbamazepine bệnh nhân là rất cần thiết để cân nhắc giữa lợi ích và nguy cơ.
Tháng 12 năm 2007 cơ quan quản lý Dược phẩm và Thực phẩm Hoa Kỳ (FDA) đã khuyến cáo sàng lọc alen HLA-B*1502 trước khi điều trị bằng carbamazepine đặc biệt chủng tộc người châu Á. Việt Nam là nước nằm trong khu vực có tần suất lưu hành cao HLA-B*1502. Hơn nữa tình trạng sử dụng carbamazepine một cách rộng rãi trong thực hành lâm sàng sẽ làm tăng nguy cơ dị ứng carbamazepine và tăng gánh nặng kinh tế cho toàn xã hội. Do vậy việc xác định người mang alen HLA-B*1502 là rất cần thiết, nhằm giảm thiểu nguy cơ dị ứng nặng do carbamazepine cho bệnh nhân.

\section{KẾT LUẬN}

Ca bệnh hội chứng Stevens-Johnson (SJS) là phản ứng dị ứng nặng với thuốc điều trị chống động kinh carbamazepine có alen HLA-B*1502 dương tính. Động kinh là một bệnh không hiếm gặp tại Việt Nam vì thế các bác sĩ tại các cơ sở y tế nên cân nhắc sàng lọc alen HLA-B*1502 trước khi điều trị bằng carbamazepine.

\section{TÀI LIỆ THAM KHẢO}

1. James W. Antoon, Jennifer L. Goldman, Brian Lee, Alan Schwarts. Incidence, outcomes, and resource use in children with Stevens-Johnson syndrome and toxic epidermal necrolysis. Pediatric Dermatology. 2018;1-6.

2. Nguyen Khac Dung, Tran Thuy Ngan, Nguyen T Mai Loan, et. al., Drug - induced Steven Johnsons sundrome and toxic epidermal necrolysis in Vietnamese spontaneous adverse drug reaction database: A subgroup approach to disproportionality analysis. Journal of Clinical pharmacy and therapeutics. 2018; 1-9. 
3. Chen, P. et al. Carbamazepine-induced toxic Văn Đoàn (2015), “HLA-B*1502 và carbamazepine effects and HLA-B*1502 screening in Taiwan. N. tổn thương da nặng tại Việt Nam", Asia Pac Allergy, Engl. J. Med. 364, 1126-1133 (2011). tr. 68-77.

4. Nguyen Van Dinh, et. al., The association

6. Nguyễn Văn Đoàn và Nguyễn Ngọc Phúc between the presence of HLA B*1502 and (2000), “Bước đầu nghiên cứu dị ứng thuốc tegretol carbamazepine - induced Stevens-Johnson Syndrome (SJS), Toxic Epidermal Necrolysis (TEN) and Drug- induced Hypersensitivity Syndrome with Rash, Eosinophilia and Systemic Symptoms (DRESS) in Vietnamese. The Asia Pacific Congress of Allergy, Asthma and Clinical Immunology, Taiwan.

tại khoa Dị ứng-Miễn dịch lâm sàng Bệnh viện Bạch Mai (1991-1998)", y học thực hành, số 3, tr. 17-23.

7. Nguyễn Thị Hiền (2016), Nghiên cứu đặc điểm lâm sàng, cận lâm sàng và vai trò HLA-B*1502 trong dị ứng thuốc tegretol ở trẻ em tại Bệnh viện Nhi Trung ương từ năm 2011-2016,

5. Nguyễn Văn Đĩnh, Chu Chí Hiếu và Nguyễn Luận văn Thạc sĩ Y học, Đại học Y Hà Nội. 